the high heat $\left(1,150^{\circ}\right)$ of basaltic lavas thrown out by volcanoes, and also by measurements in bore holes. But the deepest holes have penetrated considerably less than two miles of the earth's crust, and this is such an insignificant proportion of the radius of the earth (which is 4,000 miles) that it gives only a very insecure basis for the estimation of deep temperatures.

Conflicting with the theory that the sub-crustal material is fluid (which seems necessary to account for the mobility) is the fact that it behaves towards tidal forces as would a highly rigid body. Its free transmission of earthquake waves also suggests a solid earth.

Dr. Bowen outlined efforts which have been made to reconcile these conditions. One suggestion is that the interior liquid is subject to such high pressure that it exhibits characteristics of rigidity toward forces of short duration, but 'gives' as a thick fluid under the stress of long-continued forces. Another view is that the earth is entirely crystalline, but shows mobility by granular readjustment, accomplished partly by elastic effects and partly by recrystallization.

Dr. R. A. Daly, of Harvard, has proposed the theory that beneath the crust there is a shell of glassy basalt, above its melting temperature but held in an almost solid state by this intense pressure. When the pressure is released at any point the hasalt becomes a thin fluid and erupts.

Dr. Bowen's own theory involves what is termed 'selective fusion'. He believes that the basalt is a crystalline layer held under pressure near but above its crystallization temperature. As the pressure is relieved those ingredients of the rock layer which have the lowest melting point become fluid, carrying in suspension those ingredients wheh have a higher melting point and which are, therefore, still in crystalline form.

\title{
PERIODICITIES IN SOLAR VARIATION REFLECTED IN WEATHER
}

$\mathrm{D}^{\mathrm{R}}$ R. CHARLES GREELEY ABBOT, secretary of the Smithsonian Institution, in a paper at the Bicentennial Conference of the University of Pennsylvania on September 17, stated that he has found periodicities in solar variations, which range in length from 8 months to 273 months, that have continued without change of phase for at least a century. The variations under discussion do not include those short-interval sequences of rise and fall in solar variation which cover but a few days each and which govern weather changes for the subsequent two or three weeks. While these are important, he dealt with the longer cycles which have more pronounced effects on temperature and rainfall and which "through these agencies influence production, prices, and social concerns of major interest".

Observations have been made by Dr. Abbot and collaborators at stations on mountains in desert regions all over the world, where the strength of the sun's radiation can be measured with the least possible interference from local atmospheric conditions. He now has a series of measurements covering most of the days of each year since 1920, and the study of these indicates that the sun's radiation changes within the range of $0 \cdot 5-1$ per cent in cycles of the following lengths :

\begin{tabular}{|c|c|c|c|}
\hline \multicolumn{2}{|c|}{8 months } & \multicolumn{2}{|c|}{$39 \frac{1}{2}$ months } \\
\hline $9 \frac{3}{4}$ & " & $45 \frac{1}{4}$ & ," \\
\hline $11 \frac{1}{4}$ & ," & 68 & " \\
\hline 21 & ״ & 91 & ," \\
\hline $24 \cdot 9$ & , & 137 & " \\
\hline
\end{tabular}

The least common multiple of these periods is 273 months, which is approximately twice the length of the sunspot period of $11 \frac{3}{8}$ years; it may be noted that the late Prof. G. E. Hale showed that magnetism in the sunspots has a period of two sunspot cycles.

Dr. Abbot, although his daily solar observations at the Smithsonian have been carried on for only twenty years, has been able to project these cycles back through occasional solar observations made since 1905 by the Smithsonian observers at Mt. Wilson, California, and through earlier ones made in New Haven, Copenhagen and Berlin. Thus his periodicity scheme has been checked through intervals covering more than a century.

In addition to the periods mentioned, Dr. Abbot has noted sequences of approximately 46 to 92 years which have had profound effects on precipitation, as noted, for example, by the level of Lake Huron. During the ten years following 1837 it fell $5 \mathrm{ft}$. Forty-eight years later Lake Huron began a similar, but not quite so great, ten-year fall, and then in 1929 , or 92 years after the first recorded fall, there occurred another which almost exactly duplicated that of 1837. These 46- and 92-year cycles, he explained, are made up of two and four double sunspot cycles, each double sunspot cycle being 23 years.

"Although achieving moderate success in long-range forecasting by using the 23-year period and its multiples," said Dr. Abbot, "I have long hoped to get greater accuracy by building up forecasts from the effects of the individual solar periods." But the complexity of the earth and its atmosphere made this very difficult, he said, adding that "indeed the meteorologists have practically given up the use of periodicities because of unpredictable changes of phase in weather phenomenon."

But last December it occurred to Dr. Abbot that the changes of phase in weather might be caused by changes in season of the year, which, of course, are not dependent upon the sun itself but upon the movement of the earth around the sun. Since our 12-month year does not coincide exactly with any of the solar radiation cycles, obviously a point in a solar cycle does not fall on the same date every year.

"For instance," said Dr. Abbot, "if we are dealing with the $11 \frac{1}{4}$ month period, its solar cause, if unchanging in phase, will gradually march in phase through all the months of the year. Only once in 15 years will it recur in the same relationship to the months of the year, that is, on the same date. May it not reasonably be that its effect on weather may 
be different in January, when the northern hemisphere is blanketed with snow, and the atmospheric circulation is vigorous, from what its effect would be in the very different conditions prevailing in July?"

Dr. Abbot tested this on nine stations scattered. from Alaska to South Africa and is satisfied that the changes of solar radiation can be correlated with weather changes here on earth. Since each of the solar periodicities, whatever its length, has a certain least common multiple with respect to our 12 -month year, it is possible to compute dates which occur at intervals of a certain number of years and upon which the weather effect of the given solar period should recur. The 8-month period recurs in the same phase every two years, since 24 months is a common multiple of 12 and 8.

As examples of long-range forecasting based upon these periods, Dr. Abbot said that he got a 71 per cent correlation on predicting the weather in Peoria, Illinois, for five years ahead, beginning in 1935. This, the best result thus far in a number of 5-year forecasts made for various stations, covers mean monthly values of the departures from normal precipitation. Two years ago, Dr. Abbot, at the request of Vice-President Garner, made a prediction of the precipitation for San Antonio, Texas, on the basis of the 23-year sunspot cycle, and very good results were achieved.

\section{ELECTRICITY PROBLEMS IN GERMANY}

$\mathbf{I}^{\mathrm{T}}$ will have been noticed that the targets aimed at very frequently by the R.A.F. in Germany are electrical power stations. Two reasons for this are mentioned in an article in the Electrician of October 4. The first is that German industrial production, more than any other in Europe, depends on electricity, and the second that there is a great shortage of electricity due to the enormously increased demands for war production and to the exhaustion of reserves.

A few figures given demonstrate the problem which besets this part of Germany's war industry. In the year 1933, which witnessed the inception of the Nazi economy, the production of electricity was about 25,000 million kilowatt hours. Since then it has risen steadily to 36,000 million in $1935,48,000$ million in 1937, and finally 55,000 million in 1938. In 1939 still greater quantities were required, and it is unlikely that in 1940 the demand for electricity will decline. Two years ago, German experts pointed out that, owing to the special requirements for the production of substitutes and Ersatz articles, a consumption of some 100,000 million kwh. could be expected by 1943 . This is twice as much as in 1938 and four times as much as in 1933.

As yet, no way has been found to meet these requirements. German experts themselves have left no room for doubt that the peak of production, determined by the availability of the plant, etc., has already long been reached. While the consumption of electricity increased twofold between 1933 and 1938, the productive capacity of electricity works increased only by about 12 per cent. This disproportion did not constitute a serious problem so long as there were enough reserves provided for in most of the gigantic electricity plants, built in Germany since 1918 with British and American capital. According to official statements dating as far back as the end of 1938, these reserves do not exist any longer. A report of the Reich commissioner of the power industry, who early last year was appointed by Goering to increase the production of electric power, disclosed that it was difficult to cover the industrial peak requirements for electricity in the winter of 1937-38. Since that time the problem has become more acute.

The reason for this shortage lies to a considerable extent in the increase in the production of synthetic materials, which require disproportionately large quantities of electricity. One single industrial undertaking producing such synthetic substances requires an electricity plant of some 100,000 kilowatts. From the following figures published at a meeting of the Association of Electrical Engineers in 1938, it is seen that the production of, for example, 1 ton of iron requires $100-200 \mathrm{kwh}$. ; copper, $300 \mathrm{kwh}$.; synthetic rubber, 40,000 kwh.; synthetic petrol, 3,000 kwh.; textiles, 3,800 kwh.; artificial silk, 7,000 kwh.; aluminium, 20,000 kwh.; and magnesium, 44,000 kwh.

Figures concerning the aluminium industry in Germany indicate that, so early as 1938 , this branch produced 180,000 tons (which output is still far from satisfying Germany's war demands). The figure for magnesium was 100,006 tons, and the same quantity of synthetic rubber was also made. These substances, with synthetic petrol, which form only a part of the whole German Ersatz industry, require 20,000 million kwh., or two fifths of the whole 1938 consumption of power. This indicates to what extent German war production relies on electricity, and how a shortage or an interruption of electricity production is bound to hamper output.

Official estimates show that new plants of some 10 million kilowatts capacity have had to be built within a short period to meet these growing requirements. Construction on such a large scale has cost not only some 3,000-4,000 million Reichsmark, but also, a more important item, a great expenditure of time. One electricity plant cannot, in present circumstances, be constructed in less than four or five years, owing to the difficulties in the building industry and in the production of the required equipment. The shortage of skilled labour will increase these problems. The erection of power works which rely on waterpower instead of steam would take still more time. For example, five years have been provided for the construction of only one part of the new electricity plant in the Tavern district of Austria which was planned shortly before the War.

Five sixths of the electricity works in Germany depend on coal, while only one sixth is water driven. Exports of British coal amounting to 20 million tons annually have now been completely stopped. Germany's iron industry alone will soon require a 30 per cent increase in coal, owing to the use of lowgrade iron ores. 